\title{
DIÁLOGOS COM WALTER BENJAMIN SOBRE NARRATIVA: REFLETIR PARA EDUCAR
}

\section{Adriana Hoffmann Fernandes*}

Resumo: O presente artigo discute três ensaios de Benjamin nos quais a questão da narrativa está relacionada: O Narrador, Experiência e pobreza e A obra de arte na era da sua reprodutibilidade técnica. Busca perceber a relação existente entre os conceitos de narrativa e os de experiência e pobreza, aura e reprodutibilidade presente nos mesmos e, busca trazer reflexões, relacionando-as com a atualidade, algo fundamental para se educar hoje.

Palavras-chave: narrativa; Benjamin; educar

Resumen: El presente artículo discute tres ensayos de Walter Benjamin en los cuales se aborda la cuestión de la narrativa: El Narrador, Experiencia y pobreza y La obra de arte en la era de su reproductividad técnica. Se buscó percibir la relación existente entre los conceptos de narrativa y los de experiencia y pobreza, aura y reproductividad presente en los mismos. Se exponen algunas reflexiones, relacionándolas con la actualidad, que consideramos fundamentales para la educación de hoy en día.

Palabras clave: Narrativa; Benjamin; Educar

\section{Introdução}

O imperador Carlos Magno, já em avançada idade, apaixonou-se por uma donzela alemã. Os barões da corte andavam muito preocupados vendo que o soberano, entregue a uma paixão amorosa que of fazia esquecer sua dignidade real, negligenciava os deveres do Império. Quando a jovem morreu subtamente, os dignatários respiraram aliviados, mas por pouco tempo, pois o amor de Carlos Magno não morreu com ela. O imperador mandou embalsamar o cadáver e transportá-lo para a sua câmera recusando-se a separar-se dele. $O$ arcebispo Turpino, apavorado com essa paixão macabra, suspeitou que havia ali um sortilégio e quis examinar o cadáver. Oculto sob a língua da morta encontrou um anel com

\footnotetext{
* Professora da Universidade Federal do Estado do Rio de Janeiro (UNIRIO).

E-mail: hoffadri58@gmail.com
}

uma pedra preciosa. A partir do momento em que o anel passou às mãos de Turpino, Carlos Magno apressou-se em mandar sepultar o cadáver e transferiu seu amor para a pessoa do arcebispo. Turpino, para fugir daquela embaraçosa situação, atirou o anel no lago de Costança. Carlos Magno apaixonou-se então pelo lago e nunca mais quis se afastar de suas margens.

Italo Calvino

A pequena lenda escrita acima é o que Walter Benjamin chamaria de narrativa. Segundo o autor, a narrativa tem um caráter artesanal e funda-se na experiência transmitida oralmente de uma geração à outra carregando consigo a experiência daquele que a narra (narrador/contador de histórias). Quase sempre essa experiência narrativa - se abordada no ponto de vista do filósofo em questão - está fundada num interesse

Fernandes, Adriana Hoffmann. Diálogos com Walter Benjamin sobre narrativa: refletir para educar. Revista Sul-Americana de Filosofia e Educação. Número 30: nov./2018-abr.2019, p. 7-19. DOI: https://doi.org/10.26512/resafe.vi3o.28262 
prático e aparece sob a forma de um conselho carregado de sabedoria. Por isso, teve, durante muito tempo, uma forte influência na difusão de acontecimentos, pois tinha como característica a ausência de explicações, cabendo ao leitor ou ao ouvinte interpretar o que ouvia ou lia. As fábulas, os provérbios e os contos de fadas são exemplos de narrativas benjaminianas.

Ariés nos conta que na pintura e na gravura do século XVII e XVIII e na litografia pitoresca do início do século XIX o tema do contador de histórias é muito popular. No fim do século XVIII a pequena burguesia ainda conservava em algumas cidades esse passatempo. Os homens se reuniam durante o inverno nos cabarés e durante o verão nos jardins em grupos chamados de cotteries. Cada cotterie tinha pelo menos um contador de histórias. O contador de histórias era um personagem muito presente na sociedade medieval. Nela a vida acontecia em comunidade e o contador, ou narrador como chama Benjamin, era parte integrante dessa sociedade.

O tema principal desse artigo é a questão da narrativa como abordada pelo pensamento de Walter Benjamin na década de 50 trazendo reflexões para pensarmos também como esta se apresenta hoje. As reflexões de ontem e de hoje dialogam e nos fazem pensar nas transformações que vivemos. Para esse diálogo procurarei traçar uma comparação entre os aspectos comuns de três de seus ensaios nos quais a questão da narrativa está relacionada: O Narrador, Experiência e pobreza e A obra de arte na era da sua reprodutibilidade técnica. Nesses ensaios procurarei perceber a relação existente entre os conceitos de narrativa e os de experiência e pobreza, aura e reprodutibilidade.

\section{A narrativa e o narrador}

Benjamin ${ }^{3}$ em seu ensaio $O$ narrador nos fala que a arte de narrar está desaparecendo porque a sociedade que vivenciou a Primeira Guerra Mundial não consegue mais trocar suas experiências. Os choques sofridos pelas pessoas que vivenciaram a guerra e o forte desenvolvimento da técnica sobrepôs-se à experiência do homem, impedindo-o de contar e passar adiante sua história. Diante das grandes mudanças sofridas nesse período a experiência sofreu um abalo. Assim como aponta o autor são muitas as guerras que se vive hoje nas cidades do mundo (desemprego, fome, falta de moradia, violência) e todas, de alguma forma, vão pouco a pouco tirando do homem essa possibilidade de contar. A preocupação em sobreviver o impede de fazer outra coisa, o impede de olhar para o que vive, o impede de contar e de parar para ouvir. A narrativa só acontece na troca. Sem ela, morre.

Com a guerra surge uma nova barbárie; o homem, pobre de experiências, vai relegando para o segundo plano a narrativa, já que ela é a expressão mais viva dessa experiência. A pobreza substitui o tempo mais longo, o tempo vivido e elaborado em forma de sabedoria por um tempo em que se procura atingir o novo e deixar para trás as amarras da experiência. Sem ela o homem se sentiu livre, mas também perdido e desprotegido, sem referências. Sua âncora estava no passado, 
na tradição que mantinha viva a transmissão de valores de pais para filhos e que se filiava na narrativa. A modernidade chegou com as guerras e as técnicas atropelando o homem, modificando seus hábitos e sua cultura, interferindo na sua tradição.

As narrativas tradicionais se fundavam em dois tipos de narrador: o lavrador sedentário e o marinheiro mercante. $\mathrm{O}$ primeiro dava autoridade ao seu relato pela viagem, pelas histórias trazidas de longe e o segundo pelo conhecimento das tradições de sua terra. Para camponeses e homens do mar a condição de artifíce era sua academia. Ambos se tornavam narradores dentro de seu próprio ofício de artesão que tinha como princípio a transmissão da sabedoria pela experiência vivida.

As mudanças trazidas pelo capitalismo, ao interferirem no trabalho, influíram na narrativa, forma anterior de transmissão da experiência/aprendizagem. Com o domínio consolidado da burguesia surge a imprensa, instrumento de comunicação importante do capitalismo, que influencia a forma épica de modo determinante. Benjamin aponta que um dos primeiros indícios do declínio da narrativa foi o advento do romance. O que separa a narrativa do romance é que ela não depende do material impresso como o livro para existir, sua difusão ocorre pela tradição oral. Enquanto a narrativa é produzida e transmitida coletivamente, o romance é uma produção individual e tem um consumo individual; desvinculado da experiência do povo. A narrativa é uma produção que nasce e é passada adiante na coletividade. O romance nasce e é passado adiante na individualidade. Trata-se de uma mudança nas formas de se apresentarem cada um que intefere nos costumes e nas formas de contar das pessoas.

Depois do romance, a imprensa trouxe a informação, o que fez com que o homem se distanciasse cada vez mais da narrativa na concepção discutida por Benjamin. A notícia de um acontecimento que vinha de longe, tanto a distância espacial de terras como a temporal da tradição, dispunha de uma autoridade que lhe conferia validade - autoridade da experiência e da sabedoria. Com a informação esta passou a substituí-la e trazia como "autoridade" o seu caráter de realidade, de verificação do acontecimento. Isso era incompatível com o espírito da narrativa. As cotteries de que nos fala Ariès foram substituídas pelo jornal. Ele passou a ser o veículo de difusão dos acontecimentos e tornou desnecessário o encontro das comunidades para ouvir as histórias. Agora todos podiam saber dos acontecimentos pelos jornais.

A narrativa vivia nos momentos compartilhados de vida. Sua tradição desembocava numa prática comum; as histórias não eram somente lidas e ouvidas, mas escutadas e seguidas e faziam parte de uma formação válida para toda uma coletividade. Já a informação passou a ser transmitida da mesma forma em todos os lugares e para um grande número de pessoas. Ela foi feita para alcançar a massa e nela não há qualquer transmissão da experiência, conta-se o fato já explicado, isto é, já interpretado e ela morre no mesmo instante em que é contada. Seu valor é a 
novidade; não sobrevive ao tempo. A narrativa benjaminiana é artesanal e precisa do tempo para ser contada, fruída, pensada e atravessa gerações criando elos entre elas. A informação faz do tempo sua matéria, é rápida e precisa ser assimilada no menor tempo possível para que seja vista enquanto ainda é nova.

No momento em que o ritmo do trabalho muda e captura o tempo do trabalhador, a rede em que se assenta o dom de narrar se desfaz. Narrar histórias é sempre a arte de as continuar contando, passando a diante. Como não há mais tempo para se ouvir e contar histórias, a narrativa, forma artesanal de comunicação, começa a desaparecer. Tudo começa a ser abreviado e mudam a ideia de eternidade e o sentimento do tempo. Passa-se a valorizar o que é novo. A experiência adquire outro sentido nesse contexto e sua importância diminui. Hoje percebe-se que as imagens, por exemplo, parecem ser muito mais valorizadas do que as histórias narradas oralmente. A cada experiencia narrada os comentários a respeito são: "tirou foto?", "postou?", ou algo como "não precisa contar... já vi as fotos que voce postou." Essas e outras falas nos indicam essa mudança no modo de transmitir e valorizar a experiência. Será que a imagem hoje substituiu a experiência da narrativa, do contar o vivido?

Segundo Gagnebin, Benjamin reflete sobre as transformações estéticas que amadurecem no início do século XX e que modificam a produção cultural, artística e política da época. Com o início do capitalismo há uma fragmentação crescente de todos os processos vividos.
Institucionaliza-se a produção em série e o tipo de trabalho que lhe corresponde é a cadeia de montagem. Muda-se o ritmo do trabalho de acordo com o ritmo da máquina e o operário produz uma série de ações fragmentadas e descontextualizadas do conjunto da produção. Dessa forma vai extinguindo-se a experiência/sabedoria artesanal do povo. A fragmentação da produção capitalista vai sendo incorporada em outros meios e hoje percebe-se uma fragmentação até mesmo nos usos que fazemos das várias produções do mercado. Começou-se fragmentando a produção para hoje fragmentar-se até mesmo o consumo. $\mathrm{O}$ mesmo pode ter se dado com a narrativa e a experiência?

\section{A narrativa e a experiência}

Segundo Benjamin, a sabedoria do homem e sua vida vivida - matéria de onde surgem as histórias - assume forma transmissível primeiro naquele que morre. A autoridade da hora da morte está na origem da narrativa. Em grande parte dos contos a história se origina a partir da morte de um pai mais velho, de alguém experiente que ao morrer deixa aos que ficam uma lição, um pedido, uma mensagem que é passada aos demais e que é, por vezes, o motivo que percorre toda a narrativa.

A história que é apresentada no início deste texto também tem a morte como um dos fios de sua teia narrativa. Poderíamos dizer que o anel da narrativa de Calvino é uma metáfora da experiência. A experiência não morre quando morremos, mas é passada adiante assim como o anel o foi no conto de Calvino. Assim, o anel não 
tem um valor em si mesmo, mas tem valor porque traz as marcas daquele que o possui. Os que passam a possuí-lo adquirem um pouco da experiência primeira do seu dono que, no caso do conto, é o amor pela pessoa ou lugar associados ao anel. A paixão do rei pelo anel mistura a experiência do amor que foi vivido entre ele e a princesa ao próprio objeto agora representado pelo anel. O anel é único, assim como a experiência. É ele que traz as marcas do passado. Como experiência ele não morre nunca, apenas toma formas variadas e é, por isso mesmo, vivenciado diferentemente. Ele é, assim, único em cada contexto. Talvez seja essa a mágica do anel: ser sempre novo a cada novo olhar e nunca perder a dimensão da sua experiência.

Mas na sociedade capitalista a morte deixa de ser compartilhada e passa a ser afastada do homem. Se, para Benjamin, morrer e narrar têm em si laços essenciais, então o declínio histórico da narração e o afastamento social da morte andam juntos. Não se sabe mais contar e não se consegue mais morrer. Como a narração está associada à experiência, saber narrar é saber passar adiante a sua experiência que ganha uma força maior (autoridade) à beira da morte. A passagem da experiência representa a continuidade do homem que morreu na história/experiência que narrou e deixou aos que ficaram. Se o saber não mais se vincula aos outros pela experiência narrada passa a, inconscientemente, afastarse da morte. Afasta-se dos que fizeram parte dessa experiência e ajudaram a construí-la e que dessa forma também fazem parte do momento de narrá-la no contexto de sua história.
As histórias eram uma ponte entre o passado e o presente, entre o indivíduo e a tradição. A memória era a capacidade épica por excelência, era o que impelia a narrativa. A lembrança instituía a corrente da tradição que transmitia o acontecido de geração a geração como uma rede. Uma rede na qual todas as histórias (experiências) se interligavam, se complementavam, emendando uma na outra como os narradores orientais gostavam de mostrar. Gagnebin (op cit) mostra que a importância da narração para a constituição do sujeito era reconhecida por essa rememoração, ou seja, pela retomada salvadora da palavra de um passado que, sem isso, desapareceria no silencio e no esquecimento. Segundo ela, Heródoto, primeiro historiador, define sua tarefa como uma luta contra o esquecimento. Ainda hoje literatura e história enraízam-se no cuidado com o lembrar. E esse cuidado remete ao contar/recontar.

Se podemos assim ler as histórias que a humanidade conta a si mesma como fluxo da memória e, portanto, de sua identidade, nem por isso o fluxo da narração deixa de ser atravessado pelo esquecimento. No rememorar está implícito o esquecer. Se a experiência não fosse esquecida, não precisaria ser rememorada. A rememoração busca evitar o esquecimento. Jeanne Marie Gagnebin traz como exemplo a própria Odisséia, de Homero, mostrando que nela parecem se conjugar, implicitamente, a força da narração que faz esquecer e, explicitamente, uma força rememoradora, As duas constituem a narração. A atividade de narrar se compara à de Penélope, esposa 
de Ulisses durante sua viagem, tecendo durante o dia e desfazendo o tecido à noite. $\mathrm{Na}$ produção do texto se cruzam e se mesclam a atividade do lembrar e a atividade do esquecer.

Segundo Gagnebin, o pensamento de Benjamin mostra que o fim da narração e o declínio da experiência são inseparaveis das transformações profundas que a morte como processo social, sofreu no decorrer do século XIX; à substituição da idéia de tempo-eternidade pela idéia da perseguição incessante do novo, é que leva a uma redução drástica da experiência do tempo. Como o novo passa a ter maior valor que o velho, a experiência é afastada. MartimBarbero (2001) nos ajuda a lembrar que Benjamin foi o pioneiro dos estudiosos da Escola de Frankfurt por trazer a mediação fundamental que permite pensar a transformação das condições de produção com as mudanças no espaço da cultura ou, como ele dizia, as transformações do sensorium, dos modos de percepção, da experiência social. Diante dessa emergência do novo como valor foi mais do que necessário pensar a experiência da população diante desse contexto. Era preciso entender o que se passava com o povo considerando a sua experiência.

Em seu ensaio Experiência e pobreza, Benjamin se pergunta: qual o valor de todo o patrimônio cultural se a experiência não mais o vincula a nós? É preferível confessar que essa pobreza de experiência não é mais privada, mas de toda a humanidade. Surge assim uma nova barbárie. Ela o impele a partir para a frente, a começar de novo, a contentar-se com pouco e a construir com pouco. Os homens aspiram a um mundo em que possam libertar-se de toda e qualquer experiência. Um mundo cada vez mais descartável.

$\mathrm{Na}$ vida das pessoas fatigadas com as complicações da vida diária surge uma existência que se basta a si mesma, em cada episódio. São solitários os homens que fizeram do novo uma coisa essencialmente sua, com capacidade de renúncia. Essa renúncia traz uma ambiguidade, no entanto. Ao mesmo tempo em que alguns pensadores viram na falta de autoridade e de tradição não só um perigo, mas um chance de construir um mundo neutro, despojado dos antigos valores e com menos privilégios, essa ausência de vínculo pelo desejo do novo nos desvincula da memória, nos enfraquece ao valorizar mais o acontecimento-noticia de hoje do que a história-memória de ontem. Como toda mudança, temos os dois lados dessa percepção. Hoje estamos vivenciando essa contradição: rompemos com alguns preconceitos e tradições mas também mantivemos outros por esquecer da memória quando o novo nos atropela impedindo de ver a história.

Rouanet (1990) esclarece a ambiguidade da atitude de Benjamin diante dessa nova sensibilidade. Benjamin, ao mesmo tempo em que lamenta o fim da experiência, do vínculo com a tradição, mostra que ela traz também uma perspectiva de liberdade. Isso porque a tradição também tem seus acontecimentos negativos: a reprodução das desigualdades, as injustiças na forma de contar a história sob o ponto de vista dos vencedores... Romper com a tradição poderia significar a construção de uma história nova e mais 
justa. Esse é também o entendimento de todos os que nos ajudam a pensar que a narrativa pode estar sobrevivendo nessas novas histórias que vnao sendo contadas por diferentes públicos que anteriormente não eram visibilizados pela sociedade.

\section{A narrativa e a "aura”}

Benjamin aponta que com a reprodutibilidade técnica o que se atrofia na obra de arte, assim como na narrativa, é a “aura”. A "aura” é a existência única e distante de uma obra. O aqui e o agora do original que constitui o conteúdo da sua autenticidade e unicidade. A "aura" se enraíza na tradição que identifica esse objeto até nossos dias como aquele objeto igual e idêntico a si mesmo, único. A narrativa também é sempre única, nunca será contada do mesmo jeito e, como a obra de arte, tem a sua aura, o seu "aqui e agora" - a unicidade e a distancia - que faz com que se mantenha sempre viva, nunca se esgote, mantendo seu caráter mágico ao passar de geração em geração.

Os fatores sociais que condicionam o declínio da aura derivam, para Benjamin, de duas circunstâncias estreitamente ligadas aos movimentos de massa. Uma é fazer as coisas "ficarem mais próximas" e outra é a tendência a superar o caráter único das coisas através da sua reprodutibilidade. O agente mais poderoso desta reprodutibilidade, na época de Benjamin, era o cinema. Foi através dele que a reprodutibilidade atingiu o seu ápice.

Benjamin nos mostra que a história da arte oscilou entre dois pólos: o valor de culto e o valor de exposição ou exibição. A produção artística inicia-se com imagens que servem ao culto, ao serviço da magia. $\mathrm{O}$ valor de culto de uma obra parecia também residir no mistério que a cercava. A obra era concebida, em primeiro lugar, como instrumento mágico. $\mathrm{O}$ valor de culto quase obrigava a manter secretas as obras de arte. Os temas das obras eram o homem e seu meio e a técnica usada se fundia inteiramente com o ritual. As obras eram produzidas com funções práticas de execução de atividades, ensinamento ou objeto de adoração e contemplação.

Vê-se nesse valor de culto da obra de arte aspectos semelhantes ao da narrativa. Esta também fazia parte de um ritual de encontro entre outras pessoas. Assim como a obra de arte primitiva, a narrativa tradicional também tinha o seu lado prático - o conselho - no qual vinha embutida a experiência do contador. Seus temas eram também fundados na vida do homem e era difícil separar a narrativa do narrador e da situação em que a narrativa ocorria, isto é, o homem se fundia na sua narrativa, era parte de sua constituição. Separada dele a narrativa não seria mais a mesma.

À medida em que as obras de arte perdem o seu uso ritual, aumentam as ocasiões em que podem ser expostas. $\mathrm{O}$ segredo se desfaz e, não sendo mais parte de um ritual, pode ser visto por todos. Mas essa já não é mais a mesma arte. Com a preponderância do valor da exposição a arte passa a ter funções inteiramente novas. Cumprindo um papel diferente vai ser vista e entendida de forma diferente. Benjamin reforça isso quando diz que no interior dos grandes períodos históricos a forma de percepção das coletividades humanas se transforma ao mesmo tempo que seu modo 
de existência. $\mathrm{O}$ meio em que a percepção humana se dá é condicionado historicamente. A massa é a matriz da qual emana, na contemporaneidade, uma atitude nova com relação à obra de arte. $\mathrm{O}$ número maior de participantes produziu um novo modo de participação.

Benjamin ao falar da "aura" preocupa-se em pensar sobre a "recepção" e como ela vai mudando historicamente em sua experiência. Essa experiência para Benjamin é o que Martim-Barbero (2011) nomeia como sensibilidade. As mudanças da experiência tem o sentido de transformações da percepção e portanto, da sensibilidade. E fica claro que com a reprodução a sensibilidade que muda é a sensibilidade que se refere à aproximação. Aproximar-se põe o homem na posição de usar de modo social próximo. Tira a distância da obra de arte. A aura tem também um caráter ambivalente. A obra de arte clássica tinha a sua aura e era destinada à contemplação de poucos; somente a elite tinha acesso a ela. Com a reprodução ela passa a ser recebida coletivamente. É, portanto, mais democrática. A recepção coletiva, no entanto, difere da individual e muda a relação entre a obra e o público. A reprodução ocorre mais precisamente pela fotografia e definitivamente pelo cinema. Ela muda o próprio conceito de obra de arte; passam a existir obras que já são feitas para serem reproduzidas. O cinema é o maior exemplo. $\mathrm{O}$ alto custo da produção que o envolve torna inviável concebe-lo como objeto único. Assim, ele já nasce para ser reproduzido. Sua existência já está condicionada à reprodução.
O valor de exposição também muda a situação da narrativa. Para que os acontecimentos tivessem um valor de exposição e pudessem ser acessíveis no menor tempo possível a um maior número de pessoas, eles tinham que aparecer sob a forma de informação, quando, devido à imprensa nascente, podiam ser reproduzidos para todos. A narrativa perde o seu espaço porque perde, assim como a obra de arte, o valor de culto, o ritual que a cercava e que mantinha viva a sua história. A informação tem como matéria-prima a reprodução de fatos e é contada sem a marca do narrador. Ela não faz parte de nenhum ritual, não está vinculada a nenhuma tradição e, portanto, não possui a aura da narrativa.

Na sociedade capitalista em que se fundam todas essas mudanças a técnica antecipa-se à obra e interfere nela. Transforma as obras de arte em outras obras, agora reproduzíveis. A técnica passa a ser a nossa segunda natureza e o homem começa a necessitar cada vez mais dela para realizar as atividades que antes realizava de forma artesanal. Ela muda a produção dos objetos, da arte, da história e com o tempo nos faz esquecer a aprendizagem anterior, substituindo-a pela nova que não pode mais prescindir a técnica. Passamos a viver numa sociedade em que vemos mais coisas reproduzidas do que coisas únicas criadas artesanalmente. Benjamim, no entanto, não vê nesse processo apenas o lado negativo. Ele percebe nessa mudança de percepção perdas e ganhos. Sabemos que ele considera o cinema e a fotografia como expoentes desse movimento de transformação 
histórica da sensibilidade no processo da reprodutibilidade.

\section{A reprodutibilidade e a perda da aura}

A reprodutibilidade instalou-se definitivamente com os meios de comunicação. Estes modificaram a imagem do homem, interferiram na sua "aura". Benjamin compara o papel do ator no teatro e no cinema e mostra como a reprodutibilidade da imagem do homem modificou a relação do ator com seu público. $\mathrm{O}$ ator de teatro, assim como o narrador tradicional, tem o seu público diante de si e relaciona-se com ele. Pode fazer variações na sua representação ou na narração de acordo com o contexto vivido no momento. $\mathrm{O}$ ator de cinema não tem qualquer contato com seu público no momento da produção do filme e representa o personagem de forma fragmentada.

A reprodutibilidade interferiu também na relação do povo com os seus governantes. Antes todos eram um pouco "narradores", tinham que saber contar a sua história para envolver o parlamento, os deputados e o povo. O parlamento era o seu espaço de narração. Com a evolução dos aparelhos que permitem que um número indefinido de ouvintes escutem o seu discurso e depois vejam a sua imagem, o essencial transforma-se na apresentação do homem político diante do aparelho. Esvaziam-se os parlamentos, assim como esvaziam-se os teatros e as comunidades de contadores. Esse fenômeno determina um novo processo de seleção, diante do aparelho. Assim restringe-se o papel da aura e constrói-se, artificialmente, a personalidade do ator ou do político, o que favorece ao capitalismo dos produtores, pois transformam a personalidade em mercadoria. O coletivo perde espaço em relação ao individual. Hoje predomina ainda a construção de um eu personagem (como discute Sibilia em seu livro) tanto na política quanto na arte, como nas pessoas comuns.

Fazendo uma relação com os dias atuais, os meios de comunicação e a reprodutibilidade da obra e da mensagem transformam em valor a exposição, ou seja, tudo o que pode ser mostrável. Dessa forma o valor do que se mostra pode ser maior do que a coisa em si, ou seja, qualquer coisa pode se supervalorizar ao ser mostrada, simplesmente pelo fato de aparecer, não importa sob que circunstâncias. Na contemporaneidade parece que esse valor de exposição exacerba-se. Presenciamos hoje programas na televisão que têm como filão a pura e simples exposição das pessoas em situações vividas no dia-a-dia como é o caso dos programas que já existiram (No Limite e Casa dos Artistas) e outros que ainda existem há mais de 10 anos como Big Brother. O valor de exposição cresceu a ponto de hoje ser um valor "em si”. É também o caso do crescimento dos youtubers que abrem canais pessoais divulgando suas intimidades transformando-se num "show do eu" como analisa Sibilia (2016) em seu livro ao analisar esse processo de extimidade, pelo crescimento desse costume de exposição da intimidade. A exposição torna-se um valor e Benjamin já nos idos de 1950 vislumbrava essa mudança perceptiva e fazia relações 
que ampliaram-se bastante até os dias atuais.

O sistema capitalista, com todas essas mudanças, exacerbou a diferença entre público e privado. Os valores individuais substituíram as certezas coletivas. A história do si foi pouco a pouco preenchendo o espaço vazio deixado pela história comum. Há uma ruptura com o lado artesanal do trabalho, das relações, da narrativa; todos os que se fundavam na coletividade. Em contrapartida, o homem passa a ser visto como indivíduo e não como coletivo. A separação entre público/coletivo e privado/individual hoje interfere não só na produção como nas relações.

Benjamin ressalta que à produção em massa corresponde a reprodução das massas. Nos grandes desfiles nos comícios gigantescos, nos espetáculos esportivos, todos captados pelos aparelhos de filmagem, a massa vê o seu rosto. Hoje sabe-se que há acontecimentos que são pensados em função de sua transmissão na tela da TV e dizemos que também nas telas dos celulares nas transmissões ao vivo de canais do youtube ou mesmo de aplicativos como instagram. Os movimentos de massa são uma forma de comportamento humano que corresponde à técnica dos aparelhos. Antes deles não existia a massa, porque ela não podia ser vista, mostrada. A reprodução da produção é que criou o conceito de massa. Essa idéia de ser visto por muitos, de forma coletiva. $\hat{E}$ essa uma forma de recepção em que - como analisa MartimBarbero (2001) - a massa "submerge em si mesma a obra artística”, o que Benjamin via como um modo positivo de percepção baseada na dispersão, na imagem múltipla e na montagem.

$\mathrm{O}$ que caracteriza o cinema e os meios de comunicação em geral não é apenas o modo pelo qual o homem se apresenta ao aparelho, é também a maneira pela qual, graças a esse aparelho, ele representa para si o mundo que o rodeia. Era a narrativa que, antes, expressava a forma de pensar da comunidade; era o modo pelo qual se integravam, se relacionam, aprendiam e representavam-se a si mesmos. A narrativa produzia o homem e o homem a produzia. Era o elemento de formação de sua humanidade. Hoje os meios de comunicação exercem em parte esse papel. Como bem lembra MartinBarbero (op cit) foi a operação de aproximação que trouxe o declínio do velho modo de recepção que correspondia ao valor "cultural" da obra e a passagem para outro: o valor da "exposição".

Benjamin nos diz que os dadaístas, como reação à reprodutibilidade nascente na época, aniquilavam a "aura" de suas criações e as estigmatizavam como reprodução. Ao recolhimento das obras anteriores opõe-se a distração dessas obras como uma variedade do comportamento social. O dadaísmo transforma a obra de arte em objeto de escândalo, pois ela tinha que satisfazer a uma exigência básica: chocar a opinião pública. Na verdade esse não deixava de ser também o princípio da informação. Esta procurava, e ainda procura, não contar uma história, mas atrair o olhar do público com manchetes intrigantes. Até hoje o jornal ainda utiliza a intenção de chocar o público para fazê-lo ter interesse em ler notícia. Nem sempre 
seu objetivo é informar mas muitas vezes é trazer o público para perto mesmo sem ter as informações necessárias. Isso nos mostra como o valor da exposição aumenta cada vez mais. Com essa nova forma de relação em que a distração é a base percebe-se que ampliam-se cada vez mais as produções que vão sendo reproduzidas ampliando a discussão inicialmente levantada por Benjamin.

O choque da mudança constante de ângulos no cinema aparece na informação sob a forma da mudança de assunto. A cada dia novas informações são publicadas e com o volume de informações, assim como no cinema com o volume de imagens, nem sempre é possível uma reflexão. A cada imagem do cinema sobrepõe-se uma outra; e a cada informação sobrepõe-se uma mais nova. Como as informações já vinham devidamente explicadas, por vezes, passaram a ser um novo veículo de formação dos homens. Essa reflexão trazida por Benjamin nos ajuda a pensar também sobre esses "choques da mudança" nas nossas relações com os diferentes meios de comunicação da atualidade. Essa discussão que começou com o cinema e com o jornal hoje continua firme alargando-se para a internet e as diferentes telas com as quais convivemos diariamente. $\mathrm{E}$ onde ficou a narrativa em todo esse contexto de mudanças da sensibilidade?

\section{A narrativa na contemporaneidade}

Arrisco-me a dizer que a narrativa não está esquecida. Está mudada. Com outras vestes, talvez outro nome, outra forma e modo de apresentar-se. Por isso, talvez uns digam que ela morreu. Morreu uma idéia de contar e sentir trazida por Benjamin e vivida nas comunidades tradicionais que já não existe mais nos moldes atuais das grandes metrópoles. Surgiram outras. Talvez Benjamin - se estivesse vivo hoje - até quisesse refletir sobre as novas formas de narrar atuais.

Podem ser chamadas de narrativas talvez somente a retomada do compartilhar coletivo das histórias sob a forma profissional dos grupos de contadores que se preparam para compartilhar com os ouvintes as histórias de seu repertório? Histórias tanto de histórias populares da boca do povo sem autor definido como também as de livros contadas e compartilhadas oralmente com troca e transmissão de sabedoria? Vemos hoje grupos de contadores de história que coletam histórias e percorrem o país contando e recontando histórias. Buscam recriar um espaço de narração que antes, como comentamos, era público e fazia parte das cidades e dos modos de viver em comunidades e hoje para ser vivido precisa ser trazido e recriado nos espaços em que habitamos.

E que outras narrativas podem existir hoje fora essa dos contadores de histórias? Pode essa narrativa hoje estar misturada às diferentes linguagens dos diferentes meios de comunicação?

$E$, se considerarmos que a narrativa tem esses aspectos aqui levantados de produção oral, fundada na coletividade será que as produções atuais nos canais do youtube com foco na exibição da intimidade ou (ex)timidade como discute Sibilia (2016) são narrativas? Será que as produções da TV produzidas sob a ótica na 
reprodutibilidade destinadas à massa são narrativas? Será que as histórias compartilhadas nas redes sociais em relatos pessoais de situações sociais vividas são narrativas? E se não são narrativas no sentido discutido por Benjamin podem ser outros tipos de narrativas? Que nome daríamos a elas?

Percorre-se o grande caminho da história do homem na condução da aprendizagem do homem, criança jovem ou adulto de hoje. Da oralidade para a leitura. Do coletivo para o individual. Do ouvir para o ver. Podemos nos arriscar a dizer que hoje a narrativa mudou. Os modos de perceber e sentir já não são mais os mesmos da época em que Benjamin começou a vislumbrar essas mudanças. Não temos narrativas auráticas nas narrativas da mídia. Mesmo assim as reflexões desse filósofo nos ajudam sobremaneira a pensar sobre nosso vínculo com os modos de contar nos dias de hoje. E nos mostram que ao mudarem os tempos, mudam os modos de narrar e os conceitos de narrativa.

As histórias existem hoje de outra forma sendo contadas, lidas ou vistas no cinema, livro ou qualquer outro veículo mas não tem mais o vínculo com a produção artesanal na troca coletiva de experiências. Benjamin nos ajuda a perceber a necessidade de recuperá-las, de rememorálas impedindo o seu esquecimento. A narrativa já não é mais elemento de união e formação de uma coletividade e hoje convive com os diferentes veículos de difusão do conhecimento que existem na atualidade, como Internet, jornal, livro, vídeo, TV, cinema, passando a ser um, dentre os muitos elementos de conhecimento existentes. A informação presente na maioria desses meios continua a ser preponderante e é um dos valores fundamentais do século XXI. A valorização da informação faz com que os diferentes veículos a busquem e - muitas vezes - o homem fica perdido diante da sua infinidade. Mas mesmo esse homem perdido do século XXI lembra muito bem dos tempos em que ouviu histórias de avó, do dia em que esteve num local de roça em que esse tipo de narrativa benjaminiana ainda vive.

Uma coisa ainda é certa. Na sociedade do desempenho, do consumo 24/7 (em que estamos 24 horas por dia conectados produzindo e consumindo informação) como é discutido por Jonathan Crary (2014) em que não podemos parar, não podemos perder oportunidades e estamos sendo atrasados, correndo, cansados e dopados como bem lembra Eliane Brum ter a oportunidade de conviver com espaços de narrativa é cada vez mais necessário e urgente. Talvez nós precisemos refletir junto com Saramago ao pensar seu ensaio sobre a cegueira para pensar se estamos produzindo homens e mulheres melhores nesse contexto de correria e mudanças constantes. Talvez precisemos relembrar mais esses momentos de troca dessa narrativa fundadora, formadora da humanidade. Mesmo não sendo mais a grande referência para o homem da cidade, que cresceu longe dela, esses momentos de narrar, ouvir e viver tem ainda hoje muito a ensinar a ele. $\mathrm{O}$ seu vigor ultrapassa o tempo e retoma os esquecidos valores da humanidade que não podemos perder. 


\section{Referências}

ARIES, Philippe. História Social da Criança e da Família. Rio de Janeiro: Guanabara, 1981. BENJAMIN, Walter. Magia e Técnica, Arte e Política - ensaios sobre literatura e história da cultura. 2a edição. São Paulo: Brasiliense, 1994. (Obras Escolhidas, vol I)

BRUM, Eliane. Exaustos, correndo e dopados. Coluna no Jornal El País, 4 de julho de 2016. Disponível em: https://brasil.elpais.com/brasil/2016/o7/o4/politica/1467642464 246482.html Acesso em agosto de 2017.

CALVINO, Ítalo. Seis propostas para o próximo milênio. São Paulo: Companhia das Letras, 1990.

CRARY, Jonathan. 24/7: capitalismo tardio e os fins do sono. São Paulo: Cosac Naif, 2014.

GAGNEBIN, Jeanne Marie. História e Narração em Walter Benjamin. São Paulo: Perspectiva. FAPESP. Campinas: editora da Unicamp, 1994.

ROUANET, Sérgio Paulo. Édipo e Anjo: itinerários freudianos em Walter Benjamin. Rio de Janeiro: edições Tempo Brasileiro, 1990.

SIBILIA, Paula. O show do eu: a intimidade como espetáculo. Rio de Janeiro: editora Contraponto, 2016.

MARTÍN-BARBERO, Jesus. Dos meios às mediações: comunicação, cultura e hegemonia. Rio de Janeiro: editora da UFRJ, 2001. 